\title{
A single dose polyanhydride-based nanovaccine against paratuberculosis infection
}

\author{
Akanksha Thukral ${ }^{1}$, Kathleen Ross ${ }^{2,3}$, Chungyi Hansen ${ }^{1}$, Yashdeep Phanse ${ }^{1,3,4}$, Balaji Narasimhan ${ }^{2,3}$, Howard Steinberg ${ }^{1}$ and \\ Adel M. Talaat ${ }^{1,3,4 凶}$
}

\begin{abstract}
Mycobacterium avium subsp. paratuberculosis (M. paratuberculosis) causes Johne's disease in ruminants and is characterized by chronic gastroenteritis leading to heavy economic losses to the dairy industry worldwide. The currently available vaccine (inactivated bacterin in oil base) is not effective in preventing pathogen shedding and is rarely used to control Johne's disease in dairy herds. To develop a better vaccine that can prevent the spread of Johne's disease, we utilized polyanhydride nanoparticles (PAN) to encapsulate mycobacterial antigens composed of whole cell lysate (PAN-Lysate) and culture filtrate (PAN-Cf) of $M$. paratuberculosis. These nanoparticle-based vaccines (i.e., nanovaccines) were well tolerated in mice causing no inflammatory lesions at the site of injection. Immunological assays demonstrated a substantial increase in the levels of antigen-specific T cell responses post-vaccination in the PAN-Cf vaccinated group as indicated by high percentages of triple cytokine (IFN- $\gamma$, IL-2, TNF-a) producing $\mathrm{CD}^{+} \mathrm{T}$ cells. Following challenge, animals vaccinated with PAN-Cf continued to produce significant levels of double (IFN- $\gamma$, TNF-a) and single cytokine (IFN- $\gamma$ ) secreting $\mathrm{CD}^{+}{ }^{+} \mathrm{T}$ cells compared with animals vaccinated with an inactivated vaccine. A significant reduction in bacterial load was observed in multiple organs of animals vaccinated with PAN-Cf, which is a clear indication of protection. Overall, the use of polyanhydride nanovaccines resulted in development of protective and sustained immunity against Johne's disease, an approach that could be applied to counter other intracellular pathogens.
\end{abstract}

npj Vaccines (2020)5:15; https://doi.org/10.1038/s41541-020-0164-y

\section{INTRODUCTION}

M. paratuberculosis is the causative pathogen of Johne's disease (JD) characterized by chronic gastroenteritis, diarrhea, weight loss and low milk yield in ruminants. ${ }^{1}$ While JD is a worldwide problem, its prevalence in the United States is estimated to be $>90 \%$ in dairy herds, ${ }^{2}$ causing a combined loss of $\$ 200-250$ million to the US dairy industry. ${ }^{3,4}$ The financial losses are incurred due to premature culling of infected animals, decreased milk production, and increased somatic cell infiltration in milk. ${ }^{5,6} \mathrm{JD}$ is a slowly progressing disease and can infect $38-40 \%$ of the herd before becoming symptomatic in a single animal. ${ }^{7,8}$ Currently there is no treatment for JD and controlling the disease progression by culling the infected animals is very expensive, whereas vaccination offers a reasonable alternative. ${ }^{9}$ Mycopar ${ }^{\circledR}$ (Boehringer Ingelheim) is an oil suspended, heat killed, whole cell vaccine licensed in the United States. However, Mycopar ${ }^{\circledR}$ fails to completely protect against $J D^{10,11}$ and can cause severe inflammatory lesions at the site of injection. ${ }^{12}$ It also poses a health risk to vaccinators due to accidental inoculation, which leads to a chronic inflammatory reaction that potentially requires surgical intervention. ${ }^{13}$ Given the challenges to control JD with the current vaccine, we directed our efforts to develop a more effective and safe vaccine against JD using polyanhydride nanoparticles (PAN).

An ideal vaccine should elicit a robust immune response without causing untoward reactions in the vaccinee or risk to the vaccinator. Another important aspect of vaccine development against Mycobacterial infection is its capability to elicit a polyfunctional $\mathrm{T}$ cell response with simultaneous production of pro-inflammatory cytokines by $\mathrm{T}$ cells. ${ }^{14,15}$ To elicit robust immunity, antigens are often formulated with adjuvants to prolong their release and enhance their protective immunity. In this study, we used whole cell lysate and culture filtrate proteins encapsulated in biodegradable polyanhydride nanoparticles (adjuvant) that provide sustained release of $M$. paratuberculosis antigens by surface erosion. ${ }^{16}$ PAN-based vaccines (i.e., nanovaccines) have been shown to impart long lasting protective immunity against several infectious diseases including influenza, pneumonic plague, respiratory syncytial virus, and pneumonia, using pathogen-specific protein antigens. ${ }^{16-22}$

The amphiphilicity of the PAN chemistry provides antigen stability and the copolymer composition enables sustained release of the encapsulated immunogens. ${ }^{21,23-27}$ The small size $(\sim 200 \mathrm{~nm})$ and large surface area of the nanoparticles allows them to carry antigens across cellular membranes and deliver them to their targets. ${ }^{28-30}$ In addition, their molecular chemistry and size has pathogen-mimicking characteristics, allowing PAN to be engulfed by, persist within, and subsequently stimulate antigen presenting cells (APCs). ${ }^{31,32}$ Polyanhydride particles on their own exhibit adjuvant-like properties by activating $\mathrm{APCs}^{31-33}$ and inducing both humoral and cell-mediated immune responses; ${ }^{17,33-35}$ formulating them with immune-stimulatory antigens results in protective immunity. ${ }^{22,35}$ Finally, these particles have been shown to be safe and induce less inflammation at the administration site compared with traditional adjuvants such as Alum and incomplete Freund's adjuvant. $^{36,37}$

M. paratuberculosis whole cell lysate and culture filtrate proteins have been shown to exhibit immunogenic properties and have previously been evaluated as a potential vaccine. ${ }^{38,39}$ Therefore, we utilized $M$. paratuberculosis antigens together with PAN to formulate nanovaccines that can elicit robust and sustainable protective immune responses. In this study, a single, subcutaneous dose of nanovaccine in C57BL/6 mice was evaluated for

${ }^{1}$ Department of Pathobiological Sciences, University of Wisconsin, Madison, WI 53706, USA. ${ }^{2}$ Department of Chemical and Biological Engineering, lowa State University, Ames, IA

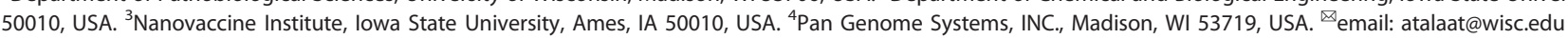


protection against $M$. paratuberculosis JTC-1285 challenge in comparison to both inactivated and live vaccine candidates. The live vaccine candidate lip $\mathrm{N}$, developed previously by our group, was constructed by knockout of a fatty acid lipase/esterase gene lipN from M. paratuberculosis K10. This gene was significantly upregulated in $M$. paratuberculosis shed in the cow feces, as revealed by transcriptional profiling. ${ }^{40}$ Also, lipN mutant was analyzed and found to be attenuated in mice as indicated by reduced histopathological lesions and colonization of the liver. ${ }^{41}$ Its protective efficacy has been observed in goats challenged by virulent $M$. paratuberculosis strain. ${ }^{42}$ The study was conducted in two phases, viz: Trial I and Trial II. In the trial I studies, the focus was on the safety of the nanovaccine formulations while in the trial II studies, the focus was on the efficacy of nanovaccine formulations (Fig. 1).

\section{RESULTS}

Nanovaccine characterization and safety

Scanning electron photomicrographs of M. paratuberculosis lysateencapsulated (PAN-Lysate) and culture-filtrate (PAN-Cf)-encapsulated polyanhydride nanoparticles showed similar spherical morphology and size as blank (i.e., empty) nanoparticles, indicating that antigen encapsulation did not change the average diameter, which was ca. $200 \mathrm{~nm}$ (Fig. 2). The encapsulation efficiency of the lysate into the nanoparticles was $40.0 \pm 1.9 \%$ and that of the culture filtrate was $26.0 \pm 0.4 \%$ and $2.5 \mathrm{wt} \%$ of the protein content of the lysate or culture filtrate (Cf) was encapsulated into the particles. To evaluate nanovaccine safety, we monitored immunized mice on a daily basis. Animals vaccinated with Mycopar ${ }^{\circledR}$ gradually developed an abscess at the injection site which progressed and persisted throughout the study (Supplemental Fig. 7). On the other hand, no lesions were observed in nanovaccine-immunized and live attenuated (lipN) vaccine immunized animals. At 6 weeks post-vaccination (WPV) and before any challenge, histopathology of vaccinated mice

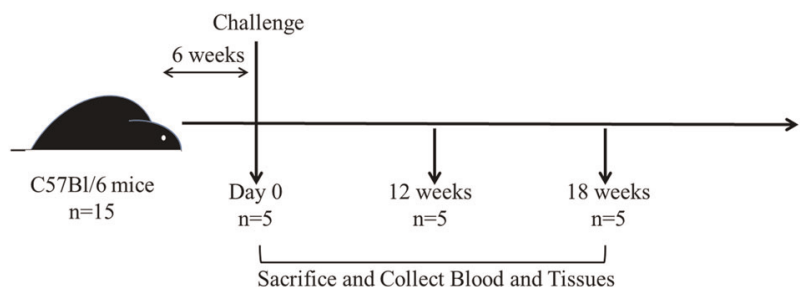

Fig. 1 Experimental design for vaccination and challenge. Five- to eight-week-old female C57BL/6 mice were vaccinated with subcutaneous injection and challenged six weeks later with virulent strain of $M$. paratuberculosis JTC-1285 by the intraperitoneal route. Mice ( $n=5 /$ group) were sacrificed at various time points. Tissues and blood samples were collected to measure bacterial burden, cytokine levels and histopathology. groups demonstrated lymphoid depletion in the spleens of animals immunized with the commercial vaccine, while minimal to moderate lymphocytic infiltration and granulomatous inflammation was observed in the livers of the rest of vaccinated animals regardless of formulation, which is indicative of induced immunity. No pathology was observed in the negative control group (PBSvaccinated mice).

\section{Pre-challenge immune responses}

For Trial I (i.e., safety study), the T cell response was evaluated at 6 weeks post-vaccination by performing IFN- $\gamma$ ELISA on spleen derived lymphocytes (described in Methods) (Supplemental Fig. 1). The Mycopar-vaccinated animals showed significantly higher IFN- $\gamma$ levels than the rest of the groups $\left({ }^{* * *} p<0.001\right)$ (Supplemental Fig. 2a). For Trial II (i.e., efficacy study), spleen derived lymphocytes were stained with various antibody markers and analyzed using flow cytometry. We assessed antigen specific, polyfunctional T cell responses by multi-parametric flow-cytometry. In this analysis, $\operatorname{LipN}$ vaccinated mice showed significantly higher percentage of double cytokine (IFN- $\gamma$, TNF- $\alpha$ ) and single cytokine (IFN- $\gamma$ ) producing $\mathrm{CD}^{+}{ }^{+} \mathrm{T}$ cells as well $\mathrm{CD}^{+}{ }^{+} \mathrm{T}$ cells in comparison with both PBS and Mycopar ${ }^{\circledR}$ vaccinated animals (Fig. $3 a, b)$. Interestingly, the percentage of triple cytokine producing (IFN- $\gamma$, IL-2, TNF-a) CD8 ${ }^{+}$T cells was significantly higher in mice immunized with PAN-Cf when compared with PBS and Mycopar ${ }^{\circledR}$. Also, the PAN-Cf vaccinated animals exhibited significantly higher double (IFN- $\gamma$, IL-2) cytokine secreting $\mathrm{CD}^{+}{ }^{+} \mathrm{T}$ cells in comparison with PBS vaccinated mice (Fig. 3b). Of note was the breadth of the polyfunctional $\mathrm{CD}^{+} \mathrm{T}$ cell response observed from mice immunized with PAN-Cf. In contrast to all the other treatment groups where the majority of the $\mathrm{CD}^{+} \mathrm{T}$ cells was dominated by IFN- $\gamma$ secreting single positive cells, PAN-Cf vaccinated mice showed a broader profile of triple, double and single cytokine secreting $\mathrm{CD}^{+} \mathrm{T}$ cells (Fig. 3b).

\section{Post-challenge immune responses}

To evaluate $\mathrm{T}$ cell response in Trial I/safety study IFN- $\gamma$ ELISA was performed and result of which depicted no significant differences in IFN- $\gamma$ levels among the groups (Supplemental Fig. 2b) while at 12 weeks post challenge Mycopar and PAN-lysate vaccinated animals showed significantly higher IFN- $\gamma$ levels as compared with control animals given PBS (Supplemental Fig. 2c). T cell responses for the Trial II/Vaccine efficacy study were evaluated by flow cytometry for which spleens from vaccinated mice were collected at 12 and 18 weeks post-challenge (WPC). At 12 WPC, multiparametric flow cytometry analysis indicated that mice immunized with PAN-Cf elicited a significantly higher percent of antigen specific double cytokine (IFN- $\gamma$, TNF- $a^{+}$) and single cytokine (IFN- $\gamma$ ) producing $\mathrm{CD}^{+} \mathrm{T}$ cells compared with non-vaccinated and Mycopar ${ }^{\circledast}$ vaccinated mice (Fig. 4). In addition, PAN-Cf and Mycopar ${ }^{\circledR}$-vaccinated animals also displayed low levels of triple cytokine secreting $\mathrm{CD}^{+}{ }^{+}$cells. Similar to the pre-challenge $\mathrm{CD} 8^{+}$ $\mathrm{T}$ immune response, mice immunized with PAN-Cf showed a
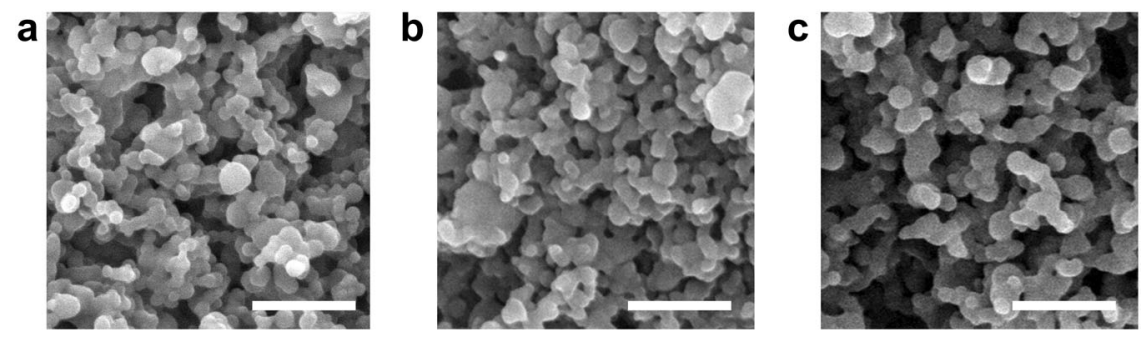

Fig. 2 Characterization of $\boldsymbol{M}$. paratuberculosis antigen-containing nanoparticle-based vaccines. Scanning electron microscopy images of 20:80 CPTEG:CPH nanoparticles loaded with $2.5 \%$ whole cell lysate (a) and $2.5 \%$ culture filtrate (b) showed similar spherical morphology and size $(\sim 200 \mathrm{~nm})$ as blank nanoparticles $(\mathbf{c})$. Scale bar $=1 \mu \mathrm{m}$. 

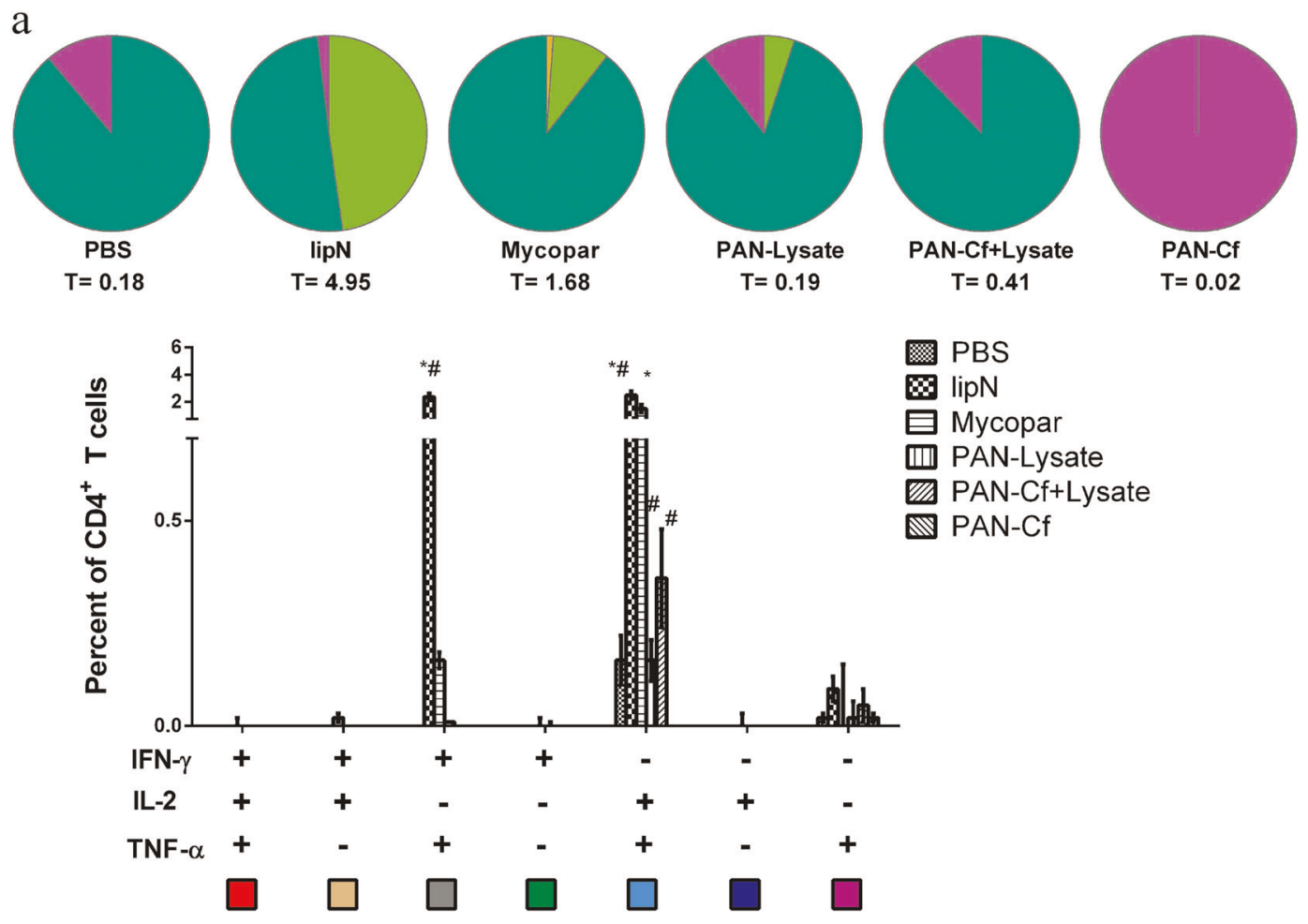

PBS

⿴囗十 lipN

目 Mycopar

III PAN-Lysate

PAN-Cf+Lysate

PAN-Cf

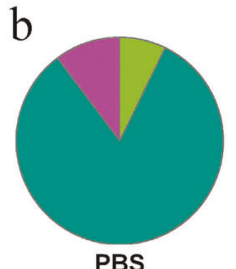

$\mathrm{T}=0.69$

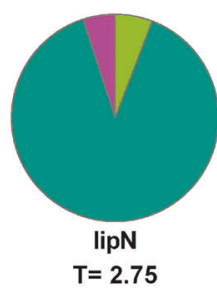

$\mathrm{T}=\mathbf{2 . 7 5}$

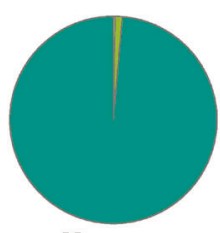

Mycopar $\mathrm{T}=1.82$

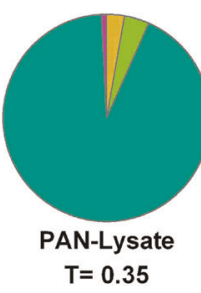

$\mathrm{T}=0.35$

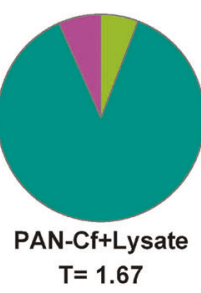

PBS

田 lipN

Mycopar

ㅁII PAN-Lysate

7 PAN-Cf+Lysate

PAN-Cf
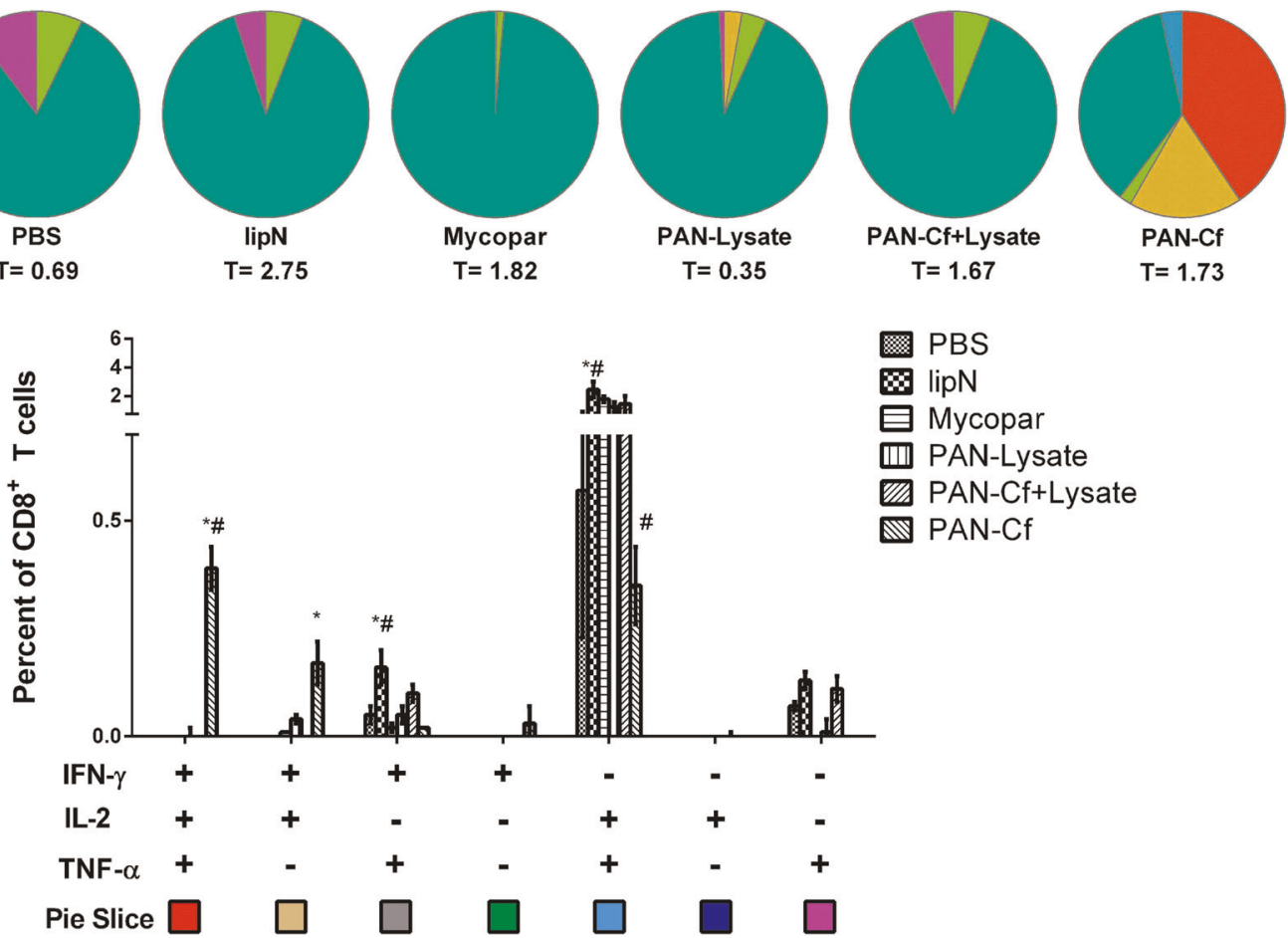

Fig. 3 Pre-challenge immune response specific to lysate of $\boldsymbol{M}$. paratuberculosis. C57BL/6 mice $(n=5)$ were immunized with various vaccine groups and 6 WPV, five mice from each group were euthanized. Spleens were harvested; lymphocytes were isolated and stimulated with the M. paratuberculosis lysate for $24 \mathrm{~h}$. Cells were then stained for CD4 ${ }^{+}(\mathbf{a})$ and $\mathrm{CD}^{+}$(b) cell surface markers and intracellular cytokines. The total percentage of T cells secreting particular cytokines are indicated below each pie chart (denoted by $\mathrm{T}=$ number). The error bars show the standard error of the mean for five individually analyzed mice. * indicates $p<0.05$; ** indicates $p<0.001 .{ }^{*}$ denotes comparison with PBS while ${ }^{\#}$ denotes comparison with Mycopar ${ }^{\oplus}$. Results were expressed as the increase in the percentage of the cells with positive staining relative to that of an unstimulated sample stained with the same antibody. 


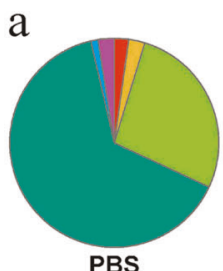

$\mathrm{T}=\mathbf{2 . 5 2}$

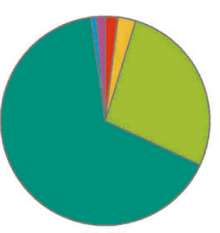

lipN

$\mathrm{T}=\mathbf{2 . 9 4}$

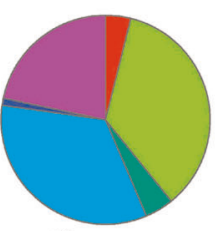

Mycopar $\mathrm{T}=\mathbf{2 . 7}$

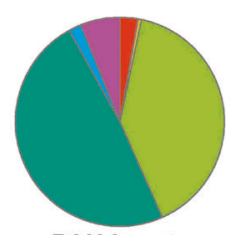

PAN-Lysate $\mathbf{T}=\mathbf{2 . 0}$

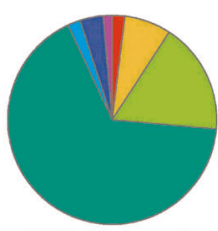

PAN-Cf+Lysate $\mathrm{T}=\mathbf{2 . 9}$



PBS

要 lipN

Mycopar

III PAN-Lysate

ש PAN-Cf+Lysate

PAN-Cf

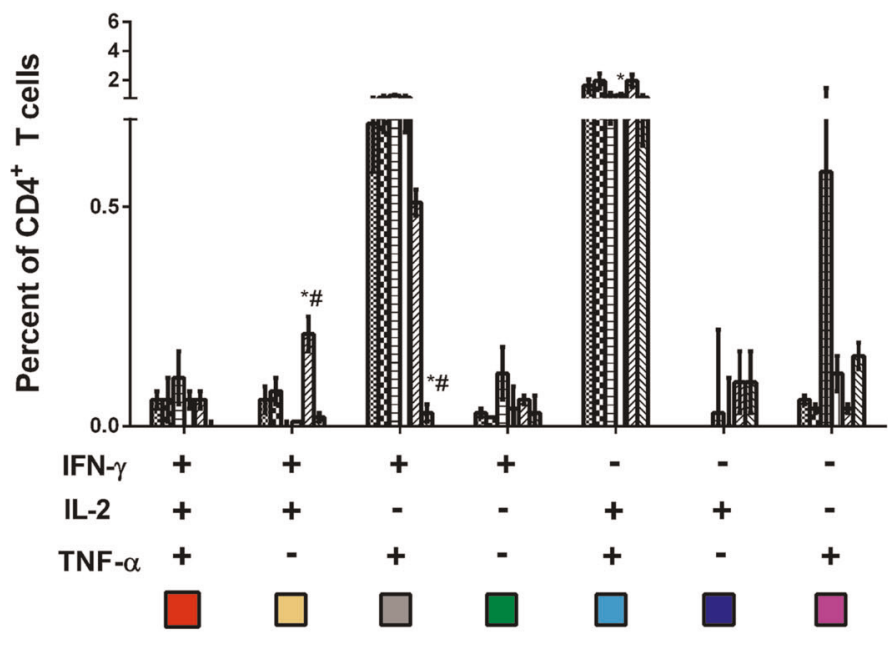

b
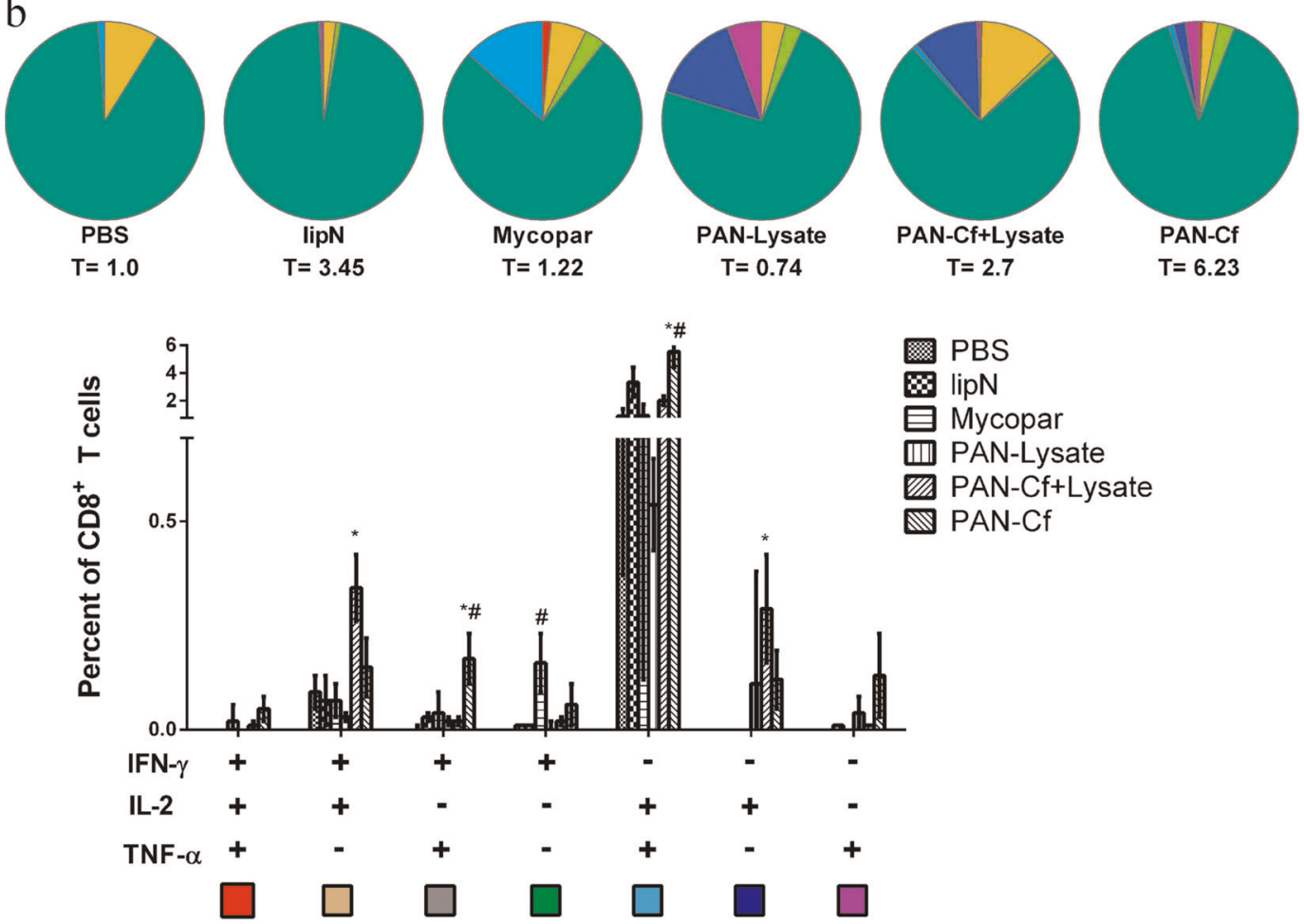

PBS

$\mathrm{Q} \operatorname{lipN}$

目 Mycopar

(II) PAN-Lysate

PAN-Cf+Lysate

PAN-Cf

Fig. 4 Early cellular responses in vaccine groups following challenge with a wild type strain of $M$. paratuberculosis. Six to eight week-old C57BL/6 mice were immunized with various vaccine candidates. At 6 WPV they were challenged with M. paratuberculosis JTC-1285 and euthanized 12 weeks later (12 WPC). The lymphocytes were isolated from the spleens and stimulated with whole cell lysate of $M$. paratuberculosis for $24 \mathrm{~h}$. Cells were then stained for $\mathrm{CD}^{+}$(a) and $\mathrm{CD}^{+}$(b) cell surface markers and intracellular cytokines and were measured by flow cytometry. The total percentage of T cells secreting particular cytokines are indicated below each pie chart (denoted by $T=$ number). The error bars show the standard error of the mean for five individually analyzed mice. * indicates $p<0.05 ;{ }^{*}$ indicates $p<0.001$. ${ }^{*}$ denotes comparison with PBS while ${ }^{\#}$ denotes comparison with Mycopar ${ }^{\circledast}$. Results were expressed as the increase in the percentage of the cells with positive staining relative to that of an unstimulated sample stained with the same antibody. 

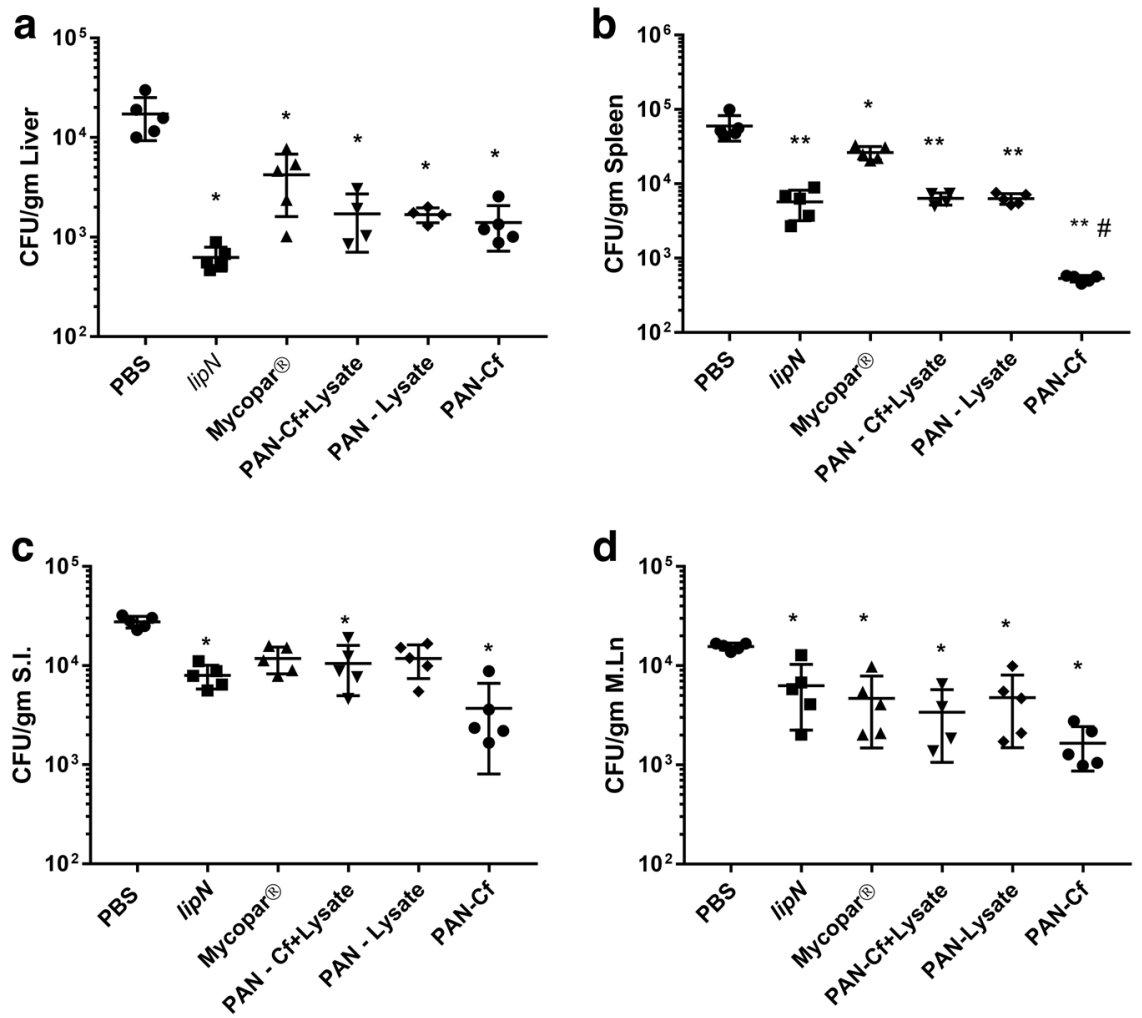

Fig. 5 Protection against challenge strain of $\boldsymbol{M}$. paratuberculosis. Levels of $M$. paratuberculosis colonization in body organs of mice at 12 WPC. The total colony counts for each individual animal for each vaccine groups are shown in spleen (a), liver (b), small intestine (c) and mesenteric lymph node (d). Error bars indicate standard deviation. ${ }^{*}$ indicates $p<0.05 ;{ }^{* *}$ indicates $p<0.001 .{ }^{*}$ denotes comparison with PBS while ${ }^{\#}$ denotes comparison with Mycopar ${ }^{\circledR}$.

broader profile of cytokine secreting cells at 12 WPC (see pie chart in Fig. 3). The cumulative percentage of $\mathrm{CD} 8^{+} \mathrm{T}$ cells that were either triple, double or single cytokine secretors was also higher in animals vaccinated with PAN-Cf (total percentage of cells secreting cytokine; $T=6.23$ ) in contrast to that in animals vaccinated with the other formulations, indicating the robustness of the induced $\mathrm{CD}^{+} \mathrm{T}$ cell response. Also, animals receiving PAN$\mathrm{Cf}+$ Lysate showed significantly higher levels of double cytokine secreting (IFN- $\gamma, \mathrm{IL}-2) \mathrm{CD}^{+} \mathrm{T}$ cells in comparison with animals that received $\mathrm{PBS}$ and significantly higher levels of double cytokine secreting (IFN- $\gamma$, IL-2) $\mathrm{CD}^{+} \mathrm{T}$ cells in comparison with animals receiving both $\mathrm{PBS}$ and Mycopar ${ }^{\circledR}$. At $18 \mathrm{WPC}$, the percentages of mycobacterial antigen-specific double positive $\mathrm{CD}^{+}{ }^{\mathrm{T}}$ and $\mathrm{CD} 4^{+}$ T cells $\left(\mathrm{IFN}-\gamma^{+} \mathrm{IL}-2^{+}\right.$) were significantly higher in PAN-Cf vaccinated mice compared with PBS-vaccinated mice (Supplemental Fig. 3).

Protection against challenge with virulent strains of $M$. paratuberculosis

In spite of the fact that safety was the main goal of the Trial I studies, we were able to evaluate the protective efficacy of each vaccine candidate at 6 WPC when bacterial colonization remained similar in organs of all vaccinated groups (Supplemental Fig. 4). At 12 WPC, the bacterial load was significantly lower in the spleens and mesenteric lymph nodes of Mycopar and PAN-Lysate and Lysate vaccinated groups in comparison with non-vaccinated group. Livers of Mycopar and PAN-Lysate vaccine group showed significant reduction in comparison with PBS group (Supplemental Fig. 5).

To better evaluate protection offered by each vaccine formulation in Trial II/Efficacy study against recent isolates of $M$. paratuberculosis, we quantified the level of bacterial tissue colonization following a challenge with $M$. paratuberculosis
JTC1285, a clinical isolate of the bovine origin. ${ }^{43}$ As expected, mice that received PBS had high levels of bacterial load in all the tissues studied (liver, spleen, intestine and mesenteric lymph node) at 12 WPC (Fig. 5). All the vaccinated mice showed significantly lower bacterial burden in the liver in comparison with PBS-treated mice (Fig. 5a). Bacterial load was significantly lower in the spleens of all vaccine groups (including Mycopar ${ }^{\circledR}$, lipN, and PAN-Lysate) with a two-log reduction observed in the spleens of animals vaccinated with PAN-Cf in comparison with the load in the spleens of animals that received PBS. The PAN-Cf immunized mice also showed significant reduction in bacterial load burden compared with Mycopar ${ }^{\circledR}$ vaccinated mice (Fig. 5b). Interestingly, Mycopar $^{\circledast}$ did not provide any protection in terms of a reduced bacterial load in the small intestine (Fig. 5c) compared with the PBS-treated animals. In contrast, mice vaccinated with lipN mutant, PAN-Cf + Lysate and PAN-Cf had significantly lower mycobacterial colonization levels in the small intestine. All mouse groups displayed a reduction in bacterial colonization of the mesenteric lymph nodes compared with the PBS control (Fig. 5c, d). At 18 WPC, no significant differences were observed in the bacterial colonization in the mouse tissues among any of the vaccine groups, including PBS (Supplemental Fig. 6).

\section{Histopathology}

To analyze the level of tissue damage induced by challenge with the wild type M. paratuberculosis JTC1285 strain, we performed histopathology of the main body organs in all vaccine groups. At 12 WPC, all animals administered PBS had granulomatous inflammation in the liver while only $40 \%$ of the animals receiving the PAN-Lysate, PAN-Cf + Lysate, or lipN vaccine exhibited minimal to mild pathology (Table 1; Fig. 6). The granulomatous lesions in livers involved variable size aggregates of lymphocytes 
Table 1. Histopathology scores of liver at 12 WPC.

\begin{tabular}{lcccccl} 
Granulomatous inflammation (GI) in liver \\
\hline Vaccine groups & \multicolumn{7}{l}{ Severity score ${ }^{\text {a }}$} & & \% of animals with Gl \\
\hline PBS & 2 & 3 & 1 & 1 & 1 & 100 \\
Mycopar $^{\circledast}$ & 2 & $\mathrm{~N}$ & $\mathrm{~N}$ & 3 & 1 & 60 \\
PAN-Lysate & 2 & $\mathrm{~N}$ & $\mathrm{~N}$ & 1 & $\mathrm{~N}$ & 40 \\
PAN-Cf + Lysate & 2 & $\mathrm{~N}$ & $\mathrm{~N}$ & 1 & $\mathrm{~N}$ & 40 \\
PAN-Cf & 1 & 1 & 1 & 1 & $\mathrm{~N}$ & 80 \\
lipN & 1 & $\mathrm{~N}$ & $\mathrm{~N}$ & 2 & $\mathrm{~N}$ & 40
\end{tabular}

${ }^{a}$ Severity index of granulomatous lesions for individual animals, as follows: $\mathrm{N}=$ normal, $1=$ minimal, $2=$ mild, $3=$ moderate, $4=$ severe, $5=$ massive
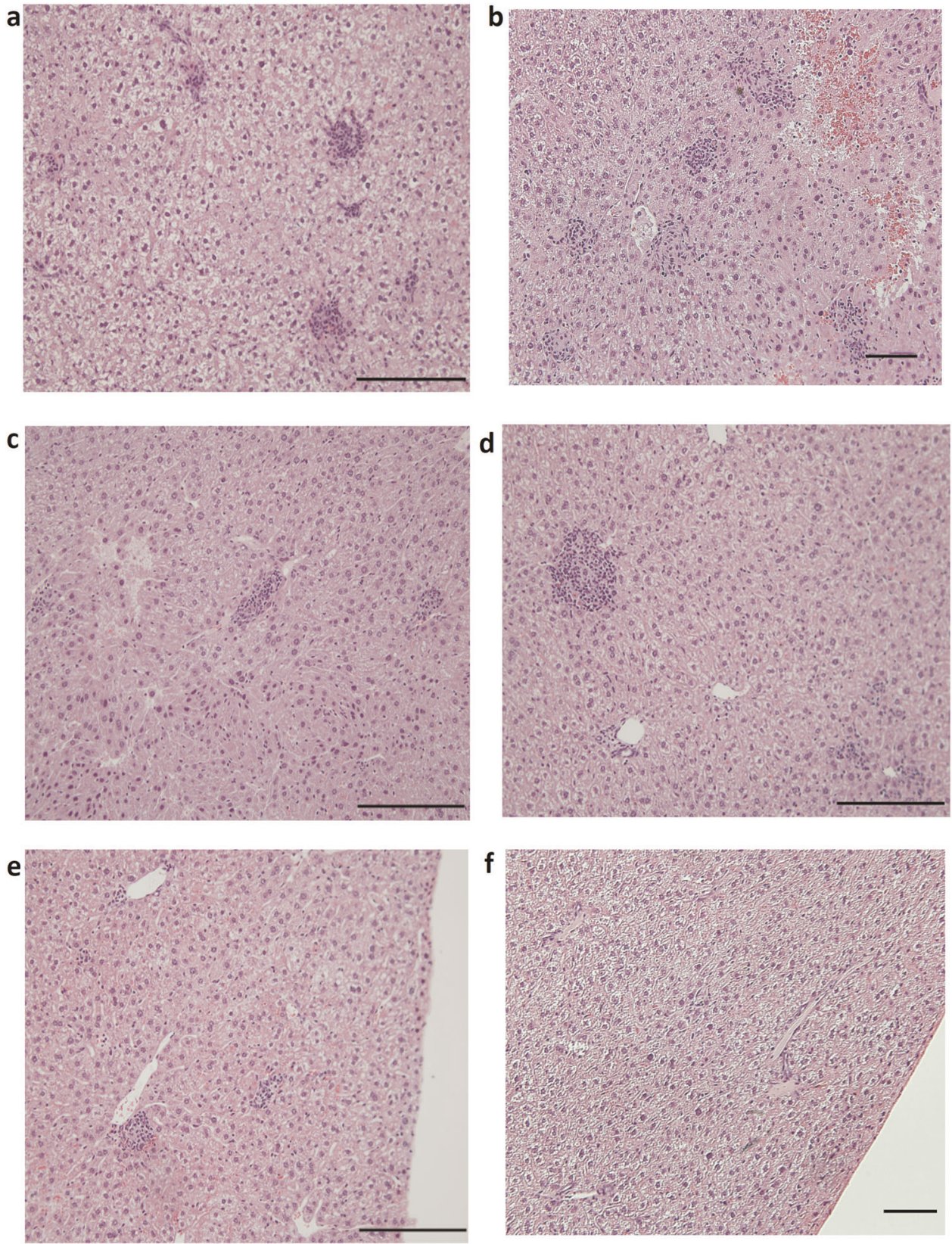

Fig. 6 Histopathology of vaccinated and challenged mice. Liver tissues from PBS (a), Mycopar ${ }^{\circledR}$ (b), lipN (c), PAN-Lysate (d), PAN-Cf + Lysate (e), PAN-Cf (f) vaccinated mice were harvested at 12 WPC. Tissues were sectioned to $5 \mu \mathrm{m}$ slices and stained with H\&E and analyzed at $20 \times$ magnification. Scale bar: $100 \mu \mathrm{m}$. 
reaction at the injection site and poor protection against bacterial tissue colonization and shedding. ${ }^{46,47}$ In this report, we utilized the polyanhydride nanovaccine platform technology to design a safer and more efficacious vaccine aginst JD. Previous studies have shown that PANs can encapuslate a diverse array of biologics including subunit proteins, peptides, and antibiotics. ${ }^{17,35}$ Here we demonstrate that polyanhydride nanoparticles can encapsulate complex payloads such as $M$. paratuberculosis proteins (from whole cell lysates and culture filtrate) and induce effective immune responses in mice indicating that the immunogenicity of the encapsulated cargo is intact. This novel delivery approach to inactivated vaccine improve their efficacy but maintain their safety profile. The strategy of using M. paratuberculosis proteins in both encapsulated and soluble form enables primed (provided by the soluble protein) and sustained (provided by the nanoparticleencapsulated protein) immune responses. ${ }^{16,33,48}$ Consistent with previous studies that examined the safety of inactivated vaccines (e.g., Mycopar $\left.{ }^{\circledR}\right),{ }^{47,49}$ we observed abscess-like lesions at the inoculation site in several mice vaccinated with Mycopar $^{\circledR}$ (Supplemental Fig. 7). In contrast, no adverse injection site reactions were observed in PAN-vaccinated mice, clearly indicating their excellent safety profile. These results add to the body of literature on the minimal reacotogenicity of polyahydride nanovaccines, as demonstrated previously. ${ }^{36,50}$

Although oral infection and mucosal immunizations against $M$. paratuberculosis could be more benificial in the target host (cattle), ${ }^{51}$ we selected parental infection and subcutaenous injection of mice to test vaccine formulas using an entery level model for vaccine testing against paratuberculosis. ${ }^{52}$ For both the murine and bovine models of paratuberculosis, $\mathrm{CD}^{+}$and $\mathrm{CD}^{+}$ effector $T$ cells play a crucial role in eliciting protective cell mediated immunity against mycobacterial infection. ${ }^{53,54}$ Effector T cells producing multiple pro-inflammatory cytokines such as IFN$\mathrm{Y}^{55}{ }^{5 N F-a^{56}}$ and IL-2 ${ }^{57}$ have been shown to be associated with protection against various intracellular pathogens including $M$. tuberculosis. ${ }^{14,15}$ Even though the exact mechanism(s) of polyfunctional T cell mediated protection are still not clear, it has been shown that two or more cytokines can work synergistically to control infection, as in the case of a closely related mycobacterium, M. tuberculosis ${ }^{58}$ and Leishmania spp. $^{59}$ Indeed, PAN-Cf vaccinated (prechallenged) mice exhibited polyfunctional $\mathrm{CD}^{+}$ $\mathrm{T}$ cells (IFN- $\gamma+, \mathrm{IL}-2+$, TNFa + ) but showed superior protection (significantly lower bacterial burden) compared with both nonvaccinated (all organs) and Mycopar (only spleen) vaccinated groups. We hypothesize that protection can be attributed to a robust polyfunctional $\mathrm{CD}^{+} \mathrm{T}$ cell response, especially for the nanovaccine formulas. Recently, nano-peptide based adjuvant enhanced BCG primed immune response by induction of a robust polyfunctional CD8 ${ }^{+}$T cells. $^{60}$ Overall, the presented analyses (Figs 3 , 4) clearly indicated robust induction of polyfunctional T cell responses in mice immunized by the nanovaccines as depicted by higher triple and double cytokine producing $\mathrm{CD}^{+} \mathrm{T}$ cells when compared with non-vaccinated (PBS) and Mycopar ${ }^{\circledR}$-vaccinated mice. It is noteworthy to mention here that for $M$. tuberculosis vaccines, polyfunctional $\mathrm{T}$ cells were mainly $\mathrm{CD}^{+}{ }^{+}$unlike the predominantly $\mathrm{CD}^{+}$population observed in animals vaccinated with the PAN-Cf group. This is likely induced by the inclusion of polyanhydride nanoparticles in the PAN-Cf group, consistent with previous observations. ${ }^{61,62}$

The nanoparticle chemistry used in this study (i.e., 20:80 CPTEG: $\mathrm{CPH}$ ) was rationally selected based on previous reports showing its potency as an adjuvant as exhibited by robust induction of cellular immune responses. ${ }^{35}$ Similarly, in this study PAN-Cf vaccinated mice at pre-challenge not only induced a polyfunctional $\mathrm{CD}^{+} \mathrm{T}$ cell response but also had more breadth as indicated by induction of more types of cytokine secreting cells. The robust polyfunctional $\mathrm{T}$ cell response observed in PAN-Cf vaccinated animals for 12 WPC may be attributed to sustained release of antigen from polyanhydride particles. ${ }^{29}$ Remarkably, PAN-Cf ${ }^{+}$Lysate was able to produce double cytokine $\left(\mathrm{IFN}-\gamma^{+} \mathrm{IL}-2^{+}\right)$ $\mathrm{CD}^{+}{ }^{+} \mathrm{T}$ cells significantly higher than PBS and Mycopar ${ }^{\circledR}$ and exhibited lower bacterial burden in all the mice tissues as compared with non-vaccinated mice (Fig. 6). Most importantly, PAN-Cf vaccinated mice had the lowest bacterial burden in three out of the four tissues evaluated. Moreover, despite this significant reduction was not maintained at 18 WPC, the level of polyfunctional $T$ cells remained robust at this prolonged time. This indicates that several other paramters (beyond the scope of present study), such as Th-17 induction, tissue homing properties of T cells, memory and effector phenotype could also play critical roles. ${ }^{6,64}$ These parameters deserve more attention, especially as we advance vaccine testing to ruminant models.

As expected, histological lesions post-challenge correlated with protection based on bacterial burden in body organs. For example, granulomatous lesions that are typical of mycobacterial infection were seen in the liver of PBS and Mycopar ${ }^{\circledR}$-vaccinated animals in higher frequency than in the lipN or PAN-vaccinated animals (Table 1), consistent with the levels of mycobacterial colonization. Similar to other vaccine candidates (lipN mutant), PAN-based vaccines were able to significantly lower $M$. paratuberculosis levels in the liver, spleen and lymph nodes but did not prevent dissemination of infection. Approaches focused on developing significant mucosal immunity at the main site of $M$. paratuberculosis entry (intestine) could definitely reduce organ dissemination of the infection. Overall, the nanovaccines and lipN mutant were able to impart superior protective imunity against $M$. paratuberculosis challenge in mice compared with a commercial vaccine, Mycopar ${ }^{\circledast}$. Further, in contrast to Mycopar ${ }^{\circledR}$, nanovaccines were also well tolerated and did not induce any adverse reactions at the site of injection. Both these features makes PAN nanovaccines ideal for further testing in larger animals such as goats and cattle following mucosal immunization and oral infections, to memic natural infection. Although promising, nanovaccines have room for improvement before becoming suitable for field applications. For example, methods to improve the encapsulation efficiency of complex protein mixtures like whole cell lysate into PAN are highly desirable and if developed, could improve vaccine production and facilitate immunization. Such strategies could open the door for the development of more effective vaccines targeting other intracellular pathogens such as M. tuberculosis.

\section{METHODS}

Bacterial strains and growth conditions

For safety experiments, $M$. paratuberculosis $-\mathrm{K} 10$ was used to prepare lysate while for efficacy experiments, M. paratuberculosis strain JTC-1285 was used to derive lysate and culture-filtrate (Cf) proteins for vaccine formulation. Both isolates belong to C-type of $M$. paratuberculosis with almost identical genomes. ${ }^{43}$ The same strains were used for the animal challenge studies, as described below. The strains were grown in Middlebrooks $7 \mathrm{H} 9$ broth (Difco, Sparks, MD) supplemented with $0.5 \%$ glycerol (v/v) and 10\% (v/v) ADC (albumin, dextrose, catalase) or Tween 80 and $1 \mathrm{mg} / \mathrm{mL}$ mycobactin J (Allied Monitor, Fayette, MO) in a shaking incubator at $37^{\circ} \mathrm{C}$ until it reached the log phase $\left(\mathrm{OD}_{600}=0.5-1.0\right) .^{43}$ The $M$. paratuberculosis field isolate, JTC-1285, was sub-cultured in Watson Reid medium, ${ }^{65,66}$ modified by supplementing $1 \mathrm{mg} / \mathrm{mL}$ mycobactin J (Allied Monitor, Fayette, MO). The Watson Reid medium enabled culture filtrate proteins to be analyzed free of bovine serum albumin (BSA) contamination. The live attenuated vaccine strain, M. paratuberculosis $\Delta$ lipN mutant (lipN mutant) was constructed by an in-frame deletion of $1.1 \mathrm{~kb}$ of the lipN gene from $M$. avium subsp. paratuberculosis strain $\mathrm{K}-10$ and grown in Middlebrooks $7 \mathrm{H} 9$ broth in presence of $30 \mu \mathrm{g} / \mathrm{mL}$ hygromycin. ${ }^{40}$ This vaccine construct was used as a control to evaluate nanovaccine performance. 
Table 2. Vaccine groups used in Trial I and Trial II.

\begin{tabular}{lll}
\hline & Group & Dosage of protein \\
\hline Trial I $^{\text {a }}$ & PAN-Lysate & $75 \mu$ g soluble $+25 \mu \mathrm{g}$ encapsulated \\
& Lysate (no PAN) & $100 \mu \mathrm{g}$ soluble \\
& Mycopar & $100 \mu \mathrm{L}$ \\
& PBS & $100 \mu \mathrm{L}$ \\
Trial II & \\
& PAN-Lysate & $75 \mu \mathrm{g}$ soluble $+25 \mu \mathrm{g}$ encapsulated \\
& PAN-Cf & $75 \mu$ g soluble $+25 \mu \mathrm{g}$ encapsulated \\
& PAN-Cf + Lysate & $75 \mu \mathrm{g}$ soluble $+25 \mu \mathrm{g}$ encapsulated \\
& LipN & $10^{8}$ C.F.U. \\
& Mycopar & $100 \mu \mathrm{L}$ \\
& PBS & $100 \mu \mathrm{L}$ \\
\hline aLysate obtained from M. paratuberculosis K10. \\
bLysate obtained from M. paratuberculosis JTC-1285.
\end{tabular}

Preparation of culture filtrate and lysate protein

M. paratuberculosis K10 and JTC-1285 cultures were centrifuged in preweighed $50 \mathrm{~mL}$ conical tubes at $3200 \times g$ for $15 \mathrm{~min}$ at room temperature. The supernatant was filter sterilized with $0.22 \mu \mathrm{m}$ polyethersulfone (PES) filter (Nalgene). Further, it was size fractionated by ultrafiltration (Corning Ultra spin columns, $5000 \mathrm{MWCO}$ ) and the filtered volume retained on the membrane was dialyzed twice against $10 \mathrm{mM}$ phosphate buffered saline (PBS) ( $\mathrm{pH}$ 7.2). The concentrated culture filtrate proteins were quantified using bicinchoninic acid kit (Pierce) and stored at $-20^{\circ} \mathrm{C}$. To obtain the lysate, the bacterial cell pellet was resuspended in protein lysis buffer (100 mM Tris-Cl, $100 \mathrm{mM} \mathrm{NaCl}, 5 \mathrm{mM} \mathrm{MgCl}, 1$ mM PMSF, complete ultra protease inhibitor cocktail, $\mathrm{pH} 7.5$ ) and placed in microcentrifuge tubes containing $0.1-\mathrm{mm}$ zirconia/glass beads. Tubes were shaken in the Mini Bead-beater cell disrupter for four $45 \mathrm{~s}$ pulses followed by 1-min incubation on ice. Cellular debris and beads were pelleted by centrifugation at $3200 \times g$ for $20 \mathrm{~min}$. The supernatant was quantified for protein using bicinchoninic acid kit (Thermo Fisher Scientific, Rockford, IL) and stored at $-20^{\circ} \mathrm{C}$.

\section{Nanoparticle formulation and protein encapsulation}

Diacids of 1,8-bis(p-carboxyphenoxy)-3,6-dioxaoctane (CPTEG) and 1,6-bis (p-carboxyphenoxy)hexane (CPH) were synthesized as described in detail. ${ }^{67,68}$ Next, melt polycondensation was used to synthesize 20:80 CPTEG:CPH copolymer. The purity and molecular weight of the copolymer were verified using ${ }^{1} \mathrm{H}$ nuclear magnetic resonance spectroscopy (VXR $300 \mathrm{MHz}$, Varian, Palo Alto, CA) before proceeding to nanoparticle synthesis. Nanoparticles were synthesized using solid-oil-oil double emulsion nanoprecipitation. ${ }^{31}$ Briefly, M. paratuberculosis lysate and culture filtrate proteins were dialyzed to nanopure water by using $5 \mathrm{k}$ MWCO Spin$\mathrm{X}^{\circledast}$ UF Concentrators (Corning, Corning, NY) and lyophilized overnight. The 20:80 CPTEG:CPH polymer $(20 \mathrm{mg} / \mathrm{mL})$ containing $2.5 \mathrm{wt} \%$ proteins was dissolved in methylene chloride. The solution was sonicated for $30 \mathrm{~s}$ to ensure uniform distribution of the protein throughout the solution. Particles were precipitated by pouring the solution into chilled pentane (1:250 methylene chloride:pentane) and collected via vacuum filtration. Nanoparticle size and morphology were characterized via scanning electron microscopy (FEI Quanta 250, FEl, Hillsboro, OR). The encapsulation efficiency was determined by incubating the nanoparticles in PBS at $37^{\circ} \mathrm{C}$. The released protein was quantified via a micro-bicinchoninic assay (Pierce) and compared with the amount of protein theoretically encapsulated. The final nanovaccine formulation was a combination of free protein and nanoparticle-encapsulated protein. A total of $1 \mathrm{mg}$ of nanoparticles encapsulating $25 \mu \mathrm{g}$ protein was suspended in $100 \mu \mathrm{L}$ PBS containing $75 \mu \mathrm{g}$ free protein per mouse. The mixture was sonicated for $30 \mathrm{~s}$ on ice to disperse any nanoparticle aggregates prior to administration.

\section{Mice vaccination and challenge}

Female C57BL/6 mice (5-8 weeks of age) were obtained from Taconic Inc. and maintained in bio-safety level-2 containment. All procedures were in compliance with Institutional Animal Care and Use Committee, University of Wisconsin, Madison. Experiments were run in two trials (Table 2, $n=15$ / group) with trials I and II comprising of four and six vaccine groups, respectively. Animals were vaccinated subcutaneously as per the experimental design shown in Table 2. In all experiments, five mice from each group were sacrificed at 6 weeks post-vaccination. The remaining 10 animals in each group were challenged with $10^{8} \mathrm{CFU}$ of $M$. paratuberculosis JTC-1285 in $100 \mu \mathrm{L}$ of PBS, injected intraperitoneally (IP). The subcutaneous vaccination regime and intraperitoneal challenge model has been successfully employed before in mouse models and the resulting data translated well to ruminant systems such as in goats. ${ }^{42,69,70}$ The dose was confirmed by plating the serially diluted challenge inoculums on $7 \mathrm{H} 10$ plates. Mice were monitored daily for adverse reaction(s) from vaccination and for the progression of infection. At 6 weeks (Trial I), 12 weeks (Trials I and II) and 18 weeks (Trial II) post-challenge, mice $(n=5)$ were sacrificed and the liver, spleen, small intestine and mesenteric lymph nodes were harvested from each sacrificed mouse in order to quantify the bacterial burden. Organs were homogenized in $1 \mathrm{~mL}$ PBS and undiluted and 10-fold serial diluted samples were plated onto antibiotic free and selective media (hygromycin $30 \mu \mathrm{g} / \mathrm{mL}$ ) to differentiate between lipN and challenge strain. When the selective media were not used, organs were plated onto standard $7 \mathrm{H} 10$ plates supplemented with ADC, mycobactin-J, and vancomycin $(5 \mathrm{mg} / \mathrm{mL})$, amphotericin $B(30 \mathrm{mg} / \mathrm{mL})$, and nalidixic acid $(10 \mathrm{mg} / \mathrm{mL})$ to reduce bacterial and fungal contamination. Finally, tissue sections were collected for histopathology and stained with hematoxylin and eosin. ${ }^{41}$ Slides were scored by a trained pathologist blinded to the samples. The animal experimental design is shown in Fig. 1.

\section{Splenocyte isolation and stimulation}

Spleens from five animals/group were aseptically harvested and placed in RPMI (Corning, Manassas, VA) supplemented with 1\% FBS (Atlanta biological, Lawrenceville, GA), 1\% L-glutamine (Gibco, Grand Island, NY), $1 \%$ penicillin-streptomycin (Mediatech, Inc. Manassas, VA) and $1 \%$ nonessential amino acids (Gibco). Spleens were pressed against the wire mesh screens to isolate splenocytes. The cells were washed with RPMI and resuspended in 1-2 $\mathrm{mL}$ of RBC lysis buffer (Tris buffered ammonium chloride) for $1 \mathrm{~min}$, washed, and resuspended in RPMI with 10\% FBS. Cells were counted using trypan blue dye to assess viability. A total of $10^{6}$ cells/ well were seeded into 96-well round bottom plates and stimulated with $10 \mu \mathrm{g} / \mathrm{mL}$ of whole cell lysate of $M$. paratuberculosis K10 (Trial I) or $M$. paratuberculosis JTC-1285 (Trial II) and $100 \mathrm{U} / \mathrm{mL}$ IL-2 (BD Biosciences, San Jose, CA). A control of unstimulated cells from each sample was also plated and treated with $100 \mu \mathrm{L}$ of media and $100 \mathrm{U} / \mathrm{mL}$ IL-2. Plates were incubated for $18 \mathrm{~h}$ at $37^{\circ} \mathrm{C}, 5 \% \mathrm{CO}_{2}$ followed by addition of Golgi-Plug to each well and incubated for an additional $5 \mathrm{~h}$. Cells were harvested by centrifugation and stained with immune markers to be analyzed by flow cytometry and the supernatant was used to detect IFN- $\gamma$ by ELISA.

\section{IFN- $\gamma$ ELISA}

Supernatant from the stimulated splenocytes was collected and tested for IFN- $\gamma$ levels using Mouse IFN- $\gamma$ ELISA MAX ${ }^{\mathrm{TM}}$ Deluxe kit (Biolegend, San Diego, CA) following the manufacturer's instructions. In brief, 96-well plates (Maxisorp-Immuno plates; Nunc) were coated overnight with capture antibody (monoclonal capture antibody specific for mouse IFN- $\gamma$ ) at 1:200 dilutions in the coating buffer at $4^{\circ} \mathrm{C}$. Plates were washed with PBST $\left(137 \mathrm{mM} \mathrm{NaCl}, 2.7 \mathrm{mM} \mathrm{KCl}, 10.15 \mathrm{mM} \mathrm{Na}_{2} \mathrm{HPO}_{4}, 1.76 \mathrm{mM} \mathrm{KH}_{2} \mathrm{PO}_{4}, \mathrm{pH} 7.4\right.$, $0.05 \%(\mathrm{v} / \mathrm{v})$ Tween 20), blocked with $200 \mu \mathrm{L}$ of assay diluent, and incubated on a shaking plate for $1 \mathrm{~h}$ at room temperature. Plates were washed five times with the PBST and $100 \mu \mathrm{L}$ of sample and standards were added to the appropriate wells and incubated for $2 \mathrm{~h}$ on the shaking plate. Plates were washed with PBST and $100 \mu \mathrm{L}$ of detection antibody (biotinylated rat monoclonal anti-mouse antibody) was added and incubated for $1 \mathrm{~h}$ at room temperature. After three more washes, $100 \mu \mathrm{L}$ of Avidin-horse radish peroxidase conjugated solution was added to each well and incubated for $30 \mathrm{~min}$ on the shaking incubator. After a last few washes, $100 \mu \mathrm{L}$ of freshly made $3^{\prime}, 3,5,5^{\prime}$-tetramethylbenzidine (TMB) substrate solution was added to the wells and incubated for $20 \mathrm{~min}$ in the dark. The reaction was stopped by adding $100 \mu \mathrm{L}$ of stop solution $\left(1 \mathrm{~N} \mathrm{H}_{2} \mathrm{SO}_{4}\right)$. The plates were read at a wavelength of $450 \mathrm{~nm}$ and analyzed with SoftMax Pro software (Molecular Devices, Sunnyvale, CA).

\section{Flow cytometry}

Splenocytes from five individual mice per group were counted and $1 \times 10^{6}$ cells/well were plated in 96-well plates. Stimulated cells were harvested by centrifuging at $400 \times g$ for $10 \mathrm{~min}$ at $4{ }^{\circ} \mathrm{C}$. Supernatants were removed and 
cells were washed with PBS twice. Fixable Viability Dye efluor 780 (eBioscience, San Diego, CA) was diluted in PBS (1/10) and added to each well except unstained control, incubated for $30 \mathrm{~min}$ in dark at $2-8^{\circ} \mathrm{C}$ and CD16/Cd32 receptors were blocked with Fc block (BD Pharmingen, San Diego, CA). Cell surfaces were stained with cocktail of BUV496 conjugated anti-CD4 antibody, clone GK 1.5 (BD Pharmingen); BUV396 conjugated anti-CD8, clone 53-6.7 (BD Pharmingen); BV711 conjugated anti-CD25, clone PC61 (Biolegend) and incubated for $30 \mathrm{~min}$ in dark at $4{ }^{\circ} \mathrm{C}$. Cells were washed with cold FACS buffer twice and resuspended in $200 \mu \mathrm{L}$ of Fixation/Permeabilization working solution (Foxp3 staining buffer set, eBioscience, San Diego, CA). After $1 \mathrm{~h}$ incubation, cells were washed with $1 \mathrm{X}$ permeabilization buffer and stained intracellularly with APC conjugated anti-IFN- $\gamma$, clone XMG1.2 (BD Pharmingen); PE conjugated anti-IL-2 (BD Pharmingen); PEcy7 conjugated anti-TNFa, clone MP6-XT22 (eBioscience); and Alexa Fluor 780 conjugated anti-Foxp3, clone FJK16s (eBioscience). Cells were analyzed using BD FACSCalibur and data were analyzed using FlowJo software (FlowJo, LLC, Ashland, OR). Results were expressed as the increase in the percentage of the cells with positive staining relative to that of an unstimulated sample stained with the same antibody.

\section{Statistical analysis}

Statistical analysis was performed using GraphPad Prism (La Jolla, CA). Data were analyzed using one-way ANOVA followed by Tukey's multiple comparison. Results with $p<0.05$ or better were considered significant. All research reported here was conducted in accordance with all relevant guidelines and procedures, and that the work was approved by the University of Wisconsin-Madison.

\section{Reporting summary}

Further information on research design is available in the Nature Research Reporting Summary linked to this article.

\section{DATA AVAILABILITY}

All data presented in this paper are available through this report or the accompanied supplemental tables and figures.

Received: 14 February 2018; Accepted: 27 January 2020; Published online: 14 February 2020

\section{REFERENCES}

1. Hendrick, S. H. et al. Effect of paratuberculosis on culling, milk production, and milk quality in dairy herds. J. Am. Vet. Med. Assoc. 227, 1302-1308 (2005).

2. Lombard, J. et al. Herd-level prevalence of Mycobacterium avium subsp. paratuberculosis infection in United States dairy herds in 2007. Preventive Vet. Med. 108, 234-238 (2013).

3. Raizman, E. A., Fetrow, J. P. \& Wells, S. J. Loss of income from cows shedding Mycobacterium avium subspecies paratuberculosis prior to calving compared with cows not shedding the organism on two Minnesota dairy farms. J. Dairy Sci. 92, 4929-4936 (2009).

4. Ott, S. L., Wells, S. J. \& Wagner, B. A. Herd-level economic losses associated with Johne's disease on US dairy operations. Prev. Vet. Med. 40, 179-192 (1999).

5. Hasonova, L. \& Pavlik, I. Economic impact of paratuberculosis in dairy cattle herds: a review. Veterinarni Med. 51, 193-211 (2006).

6. McAloon, C. G. et al. The effect of paratuberculosis on milk yield-a systematic review and meta-analysis. J. Dairy Sci. 99, 1449-1460 (2016).

7. Magombedze, G., Ngonghala, C. N. \& Lanzas, C. Evalution of the "Iceberg Phenomenon" in Johne's Disease through Mathematical Modelling. PLOS ONE 8, e76636 (2013).

8. Kreeger, J. M. Ruminant paratuberculosis-a century of progress and frustration. J. Vet. Diagnostic Investig. 3, 373-383 (1991).

9. Bannantine, J. P. et al. A rational framework for evaluating the next generation of vaccines against Mycobacterium avium subspecies paratuberculosis. Front. Cell. Infect. Microbiol. 4, 126 (2015).

10. Köhler, H. et al. Immune reactions in cattle after immunization with a Mycobacterium paratuberculosis vaccine and implications for the diagnosis of $M$. paratuberculosis and M. bovis infections. Zoonoses Public Health 48, 185-195 (2001).

11. Uzonna, J. E. et al. Efficacy of commercial and field-strain Mycobacterium paratuberculosis vaccinations with recombinant IL-12 in a bovine experimental infection model. Vaccine 21, 3101-3109 (2003).
12. O'Neill, J. K., Richards, S. W., Ricketts, D. M. \& Patterson, M. H. The effects of injection of bovine vaccine into a human digit: a case report. Environ. Health 4, 21 (2005).

13. Patterson, C., LaVenture, M., Hurley, S. \& Davis, J. Accidental self-inoculation with Mycobacterium paratuberculosis bacterin (Johne's bacterin) by veterinarians in Wisconsin. J. Am. Vet. Med. Assoc. 192, 1197-1199 (1988).

14. Darrah, P. A. et al. Multifunctional TH1 cells define a correlate of vaccinemediated protection against Leishmania major. Nat. Med. 13, 843-850 (2007).

15. Forbes, E. K. et al. Multifunctional, high-level cytokine-producing Th1 cells in the lung, but not spleen, correlate with protection against Mycobacterium tuberculosis aerosol challenge in mice. J. Immunol. 181, 4955-4964 (2008).

16. Ulery, B. D. et al. Rational design of pathogen-mimicking amphiphilic materials as nanoadjuvants. Sci. Rep. 1, 198 (2011).

17. Huntimer, L. M. et al. Polyanhydride nanovaccine platform enhances antigenspecific cytotoxic T cell responses. Technology 2, 171-175 (2014).

18. Ross, K. A. et al. Hemagglutinin-based polyanhydride nanovaccines against H5N1 influenza elicit protective virus neutralizing titers and cell-mediated immunity. Int. J. Nanomed. 10, 229-243 (2014).

19. Phanse, Y. et al. A systems approach to designing next generation vaccines: combining a-galactose modified antigens with nanoparticle platforms. Sci. Rep. 4 3775 (2014).

20. Ulery, B. D. et al. Design of a protective single-dose intranasal nanoparticlebased vaccine platform for respiratory infectious diseases. PLOS ONE 6, e17642 (2011).

21. Haughney, S. L. et al. Retention of structure, antigenicity, and biological function of pneumococcal surface protein A (PspA) released from polyanhydride nanoparticles. Acta biomaterialia 9, 8262-8271 (2013).

22. Ross, K. et al. Combination nanovaccine demonstrates synergistic enhancement in efficacy against influenza. ACS Biomater. Sci. Eng. 2, 368-374 (2016).

23. Torres, M. P., Determan, A. S., Anderson, G. L., Mallapragada, S. K. \& Narasimhan, B. Amphiphilic polyanhydrides for protein stabilization and release. Biomaterials $\mathbf{2 8}$ 108-116 (2007).

24. Ross, K. A. et al. Structural and antigenic stability of H5N1 hemagglutinin trimer upon release from polyanhydride nanoparticles. J. Biomed. Mater. Res. Part A 102, 4161-4168 (2014).

25. Vela Ramirez, J. et al. Carbohydrate-functionalized nanovaccines preserve HIV-1 antigen stability and activate antigen presenting cells. J. Biomater. Sci., Polym. Ed. 25, 1387-1406 (2014).

26. Carrillo-Conde, B. et al. Encapsulation into amphiphilic polyanhydride microparticles stabilizes Yersinia pestis antigens. Acta Biomaterialia 6, 3110-3119 (2010).

27. Petersen, L., Phanse, Y., Ramer-Tait, A. E., Wannemuehler, M. J. \& Narasimhan, B. Amphiphilic polyanhydride nanoparticles stabilize Bacillus anthracis protective antigen. Mol. Pharmaceutics 9, 874-882 (2012).

28. Brenza, T. M. et al. Pulmonary biodistribution and cellular uptake of intranasally administered monodisperse particles. Pharm. Res. 32, 1368-1382 (2015).

29. Ross, K. A. et al. Lung deposition and cellular uptake behavior of pathogenmimicking nanovaccines in the first $48 \mathrm{~h}$. Adv. Healthc. Mater. 3, 1071-1077 (2014).

30. Haughney, S. L., Ross, K. A., Boggiatto, P. M., Wannemuehler, M. J. \& Narasimhan, B. Effect of nanovaccine chemistry on humoral immune response kinetics and maturation. Nanoscale 6, 13770-13778 (2014).

31. Ulery, B. D. et al. Polymer chemistry influences monocytic uptake of polyanhydride nanospheres. Pharm. Res. 26, 683-690 (2009).

32. Petersen, L. K., Xue, L., Wannemuehler, M. J., Rajan, K. \& Narasimhan, B. The simultaneous effect of polymer chemistry and device geometry on the in vitro activation of murine dendritic cells. Biomaterials 30, 5131-5142 (2009).

33. Kipper, M. J., Wilson, J. H., Wannemuehler, M. J. \& Narasimhan, B. Single dose vaccine based on biodegradable polyanhydride microspheres can modulate immune response mechanism. J. Biomed. Mater. Res. Part A 76, 798-810 (2006).

34. Joshi, V. B., Geary, S. M. \& Salem, A. K. Biodegradable particles as vaccine antigen delivery systems for stimulating cellular immune responses. Hum. Vaccin. Immunother. 9, 2584-2590 (2013).

35. Ross, K. A. et al. Hemagglutinin-based polyanhydride nanovaccines against H5N1 influenza elicit protective virus neutralizing titers and cell-mediated immunity. Int. J. Nanomed. 10, 229-243 (2015).

36. Huntimer, L. et al. Evaluation of biocompatibility and administration site reactogenicity of polyanhydride-particle-based platform for vaccine delivery. Adv. Healthc. Mater. 2, 369-378 (2013).

37. Vela-Ramirez, J. E. et al. Safety and biocompatibility of carbohydratefunctionalized polyanhydride nanoparticles. AAPS J. 17, 256-267 (2015).

38. Dwivedi, V. et al. Intranasal delivery of whole cell lysate of Mycobacterium tuberculosis induces protective immune responses to a modified live porcine reproductive and respiratory syndrome virus vaccine in pigs. Vaccine $\mathbf{2 9}$, 4067-4076 (2011). 
39. Sinha, S. et al. Immunogenic membrane-associated proteins of Mycobacterium tuberculosis revealed by proteomics. Microbiology 151, 2411-2419 (2005).

40. Wu, C. W., Schmoller, S. K., Shin, S. J. \& Talaat, A. M. Defining the stressome of Mycobacterium avium subsp. paratuberculosis in vitro and in naturally infected cows. J. Bacteriol. 189, 7877-7886 (2007).

41. Ghosh, P., Shippy, D. C. \& Talaat, A. M. Superior protection elicited by liveattenuated vaccines in the murine model of paratuberculosis. Vaccine 33, 7262-7270 (2015).

42. Shippy, D. C. et al. Superior protection from live-attenuated vaccines directed against Johne's disease. Clin. Vaccine Immunol. 24, https://doi.org/10.1128/ CVI.00478-16 (2017).

43. Hsu, C.-Y., Wu, C.-W. \& Talaat, A. M. Genome-wide sequence variations among Mycobacterium avium subspecies paratuberculosis isolates: a better understanding of Johne's disease transmission dynamics. Front Microbiol. 2, 236 (2011).

44. Groenendaal, H., Zagmutt, F. J., Patton, E. A. \& Wells, S. J. Cost-benefit analysis of vaccination against Mycobacterium avium ssp. paratuberculosis in dairy cattle, given its cross-reactivity with tuberculosis tests. J. Dairy Sci. 98, 6070-6084 (2015).

45. Bannantine, J. P. et al. A rational framework for evaluating the next generation of vaccines against Mycobacterium avium subspecies paratuberculosis. Front Cell Infect. Microbiol. 4, 126 (2014).

46. Sweeney, R. W. et al. Effect of subcutaneous administration of a killed Mycobacterium avium subsp paratuberculosis vaccine on colonization of tissues following oral exposure to the organism in calves. Am. J. Vet. Res. 70, 493-497 (2009).

47. Lei, L., Plattner, B. L. \& Hostetter, J. M. Live Mycobacterium avium subsp. paratuberculosis and a killed-bacterium vaccine induce distinct subcutaneous granulomas, with unique cellular and cytokine profiles. Clin. Vaccin. Immunol. 15, 783-793 (2008)

48. Goodman, J. T. et al. Nanoparticle chemistry and functionalization differentially regulates dendritic cell-nanoparticle interactions and triggers dendritic cell maturation. Part. Part. Syst. Charact. 31, 1269-1280 (2014).

49. Patton, E. A. Paratuberculosis vaccination. Vet. Clin. North Am. Food Anim. Pract. 27, 573-580 (2011). vi

50. Adler, A. F. et al. High throughput cell-based screening of biodegradable polyanhydride libraries. Comb. Chem. High. Throughput Screen 12, 634-645 (2009).

51. Stabel, J. R. \& Robbe-Austerman, S. Early immune markers associated with Mycobacterium avium subsp. paratuberculosis (MAP) infection in a neonatal calf model. Clin. Vaccine Immunol. 18, 393-405 (2011).

52. Hines, M. E. et al. Experimental challenge models for Johne's disease: a review and proposed international guidelines. Vet. Microbiol. 21, 197-222 (2007).

53. Robinson, M. W., O’Brien, R., Mackintosh, C. G., Clark, R. G. \& Griffin, J. F. T. Immunoregulatory cytokines are associated with protection from immunopathology following Mycobacterium avium subspecies paratuberculosis infection in Red Deer. Infect. Immun. 79, 2089-2097 (2011).

54. Wang, X. et al. Protection against Mycobacterium tuberculosis infection offered by a new multistage subunit vaccine correlates with increased number of IFN- $\gamma+$ IL$2+$ CD4+ and IFN- $\gamma+$ CD8 + T cells. PLoS ONE 10, e0122560 (2015).

55. Flynn, J. L. et al. An essential role for interferon gamma in resistance to Mycobacterium tuberculosis infection. J. Exp. Med. 178, 2249-2254 (1993).

56. Bean, A. G. et al. Structural deficiencies in granuloma formation in TNF genetargeted mice underlie the heightened susceptibility to aerosol Mycobacterium tuberculosis infection, which is not compensated for by lymphotoxin. J. Immunol. 162, 3504-3511 (1999).

57. Johnson, B. et al. rhulL-2 adjunctive therapy in multidrug resistant tuberculosis: a comparison of two treatment regimens and placebo. Tuber. Lung Dis. 78, 195-203 (1997).

58. Lewinsohn, D. A., Lewinsohn, D. M. \& Scriba, T. J. Polyfunctional CD4(+) T cells as targets for tuberculosis vaccination. Front. Immunol. 8, 1262-1262 (2017).

59. Bogdan, C., Moll, H., Solbach, W. \& Rollinghoff, M. Tumor necrosis factor-alpha in combination with interferon-gamma, but not with interleukin 4 activates murine macrophages for elimination of Leishmania major amastigotes. Eur. J. Immunol. 20, 1131-1135 (1990).

60. Chesson, C. B. et al. Nanoscale peptide self-assemblies boost BCG-primed cellular immunity against Mycobacterium tuberculosis. Sci. Rep. 8, 12519 (2018).

61. Wafa, E. I., Geary, S. M., Goodman, J. T., Narasimhan, B. \& Salem, A. K. The effect of polyanhydride chemistry in particle-based cancer vaccines on the magnitude of the anti-tumor immune response. Acta Biomater. 50, 417-427 (2017).

62. Zacharias, Z. R. et al. Polyanhydride nanovaccine induces robust pulmonary $B$ and $T$ cell immunity and confers protection against homologous and heterologous influenza A virus infections. Front Immunol. 9, 1953 (2018).

63. Faisal, S. M. et al. Evaluation of a Mycobacterium avium subsp paratuberculosis leuD mutant as a vaccine candidate against challenge in a caprine model. Clin. Vaccin. Immunol. 20, 572-581 (2013).
64. Settles, E. W., Kink, J. A. \& Talaat, A. Attenuated strains of Mycobacterium avium subspecies paratuberculosis as vaccine candidates against Johne's disease. Vaccine 32, 2062-2069 (2014)

65. Merkal, R. \& Curran, B. Growth and metabolic characteristics of Mycobacterium paratuberculosis. Appl. Microbiol. 28, 276-279 (1974).

66. Watson, E. Tuberculin Johnin and Mallein derived from non-protein media. Can. Public Health J. 26, 268-275 (1935).

67. Torres, M. P., Vogel, B. M., Narasimhan, B. \& Mallapragada, S. K. Synthesis and characterization of novel polyanhydrides with tailored erosion mechanisms. J. Biomed. Mater. Res. A 76, 102-110 (2006).

68. Conix, A. Poly[1,3-bis(p-carboxyphenoxy)-propane anhydride]. Macro. Synth. 2, 95-98 (1966).

69. Hines, M. E. et al. Evaluation of novel oral vaccine candidates and validation of a caprine model of Johne's Disease. Front. Cell. Infect. Microbiol. 4, https://doi.org/ 10.3389/fcimb.2014.00026 (2014).

70. Bannantine, J. P. et al. Evaluation of eight live attenuated vaccine candidates for protection against challenge with virulent Mycobacterium avium subspecies paratuberculosis in mice. Front. Cell. Infect. Microbiol. 4, https://doi.org/10.3389/ fcimb.2014.00088 (2014)

\section{ACKNOWLEDGEMENTS}

The authors would like to thank Dr. Prarthana Dharampal for her constructive feedback on this manuscript and members of the Suresh lab for providing assistance with flow cytometry experiments. This work was partially supported by grants USDA NIFA (2015-07821, 2013-67015-21347) and Animal formula fund \# WIS01814 awarded to A.M.T. B.N. and A.M.T. acknowledge support from the Nanovaccine Institute and B.N. is grateful to the Vlasta Klima Balloun Faculty Chair.

\section{AUTHOR CONTRIBUTIONS}

A.M.T. perceived the original idea and supervised the whole project. B.N. is the inventor of the P.A.N. delivery system and supervised the nanovaccine synthesis and charcaterization. A.T., K.R., C.H. and Y.P. conducted all of the experiments while H.S. was responsible for the histology analysis. All authors contributed equally to the writing and editing of the paper.

\section{COMPETING INTERESTS}

Dr. Adel M. Talaat has an ownership interest in Pan Genome Systems, INC, which is working in the area of animal vaccine development. Also, Dr. Yashdeep Phanse is currently employed by the same company.

\section{ADDITIONAL INFORMATION}

Supplementary information is available for this paper at https://doi.org/10.1038/ s41541-020-0164-y.

Correspondence and requests for materials should be addressed to A.M.T.

Reprints and permission information is available at http://www.nature.com/ reprints

Publisher's note Springer Nature remains neutral with regard to jurisdictional claims in published maps and institutional affiliations.

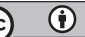

Open Access This article is licensed under a Creative Commons Attribution 4.0 International License, which permits use, sharing, adaptation, distribution and reproduction in any medium or format, as long as you give appropriate credit to the original author(s) and the source, provide a link to the Creative Commons license, and indicate if changes were made. The images or other third party material in this article are included in the article's Creative Commons license, unless indicated otherwise in a credit line to the material. If material is not included in the article's Creative Commons license and your intended use is not permitted by statutory regulation or exceeds the permitted use, you will need to obtain permission directly from the copyright holder. To view a copy of this license, visit http://creativecommons. org/licenses/by/4.0/.

(c) The Author(s) 2020 